\title{
PENGARUH PENAMBAHAN RUGAE PALATINAL PADA BASIS TIGA JENIS DESAIN OBTURATOR VELOFARINGEAL TERHADAP KUALITAS PRODUKSI BICARA PASIEN INSUFISIENSI VELOFARING PASCA PALATOPLASTI
}

\author{
(EFFECT OF PALATAL RUGAE ADDITION ON THREE KINDS OF \\ VELOPHARYNGEAL OBTURATOR DESIGNS TO IMPROVE THE \\ QUALITY OF SPEECH OF VELOPHARYNGEAL INSUFFICIENCY \\ PATIENTS POST PALATOPLASTY)
}

\author{
Amie, Edy Machmud, Elizabeth Mailoa \\ Departemen Prostodonsia \\ Fakultas Kedokteran Gigi, Universitas Hasanuddin \\ Jl.Perintis Kemerdekaan KM.10 Tamalanrea Makassar \\ E-mail: amiekamaruddin11@gmail.com
}

\begin{abstract}
Patient with cleft lip and palate is a malformation of essential component for velopharyngeal mechanism, so that the valve does not work adequately to allow proper nasopharyngeal and oropharyngeal closure, it causes difficulty in producing oral speech sound. This condition is known as velopharyngeal insufficiency. Lip and palate cleft treatment needs multidisciplinary experts such as oral and maxillofacial surgeons, plastic surgeons, otorhinolaryngologists, prosthodontists and speech therapists. One of the treatments of cleft palate is by surgery, and followed by the use of velopharyngeal obturator to improve the quality of speech. The addition of palatal rugae on obturator plate aims to recontour natural of the palatal vault, so the tongue used to the normal condition. The purpose of this study was to analyze the effect of palatal rugae addition on the velopharyngeal obturator plate to improve the quality of speech. This study was a pre-clinical experiment with pre and post control group design with three kinds of velopharyngeal obturator designs that palatal rugae to be made on each obturator. There were 12 samples divided into 3 groups, each group consisted of 4 subjects. This study examined nasal air passage, hypernasality and articulation compensation before and after the use of velopharyngeal obturator with palatal rugae addition on the plate. Data was analyzed by using the Kruskal-Walli test followed by MannWhitney post hoc test to see the difference effect of each device when pronounciation of consonant sounds and words. The result showed that all devices did not provide effect to nasal air passage. Device 1 and 3 provided the most significant influence on hipernasality, while device 2 provided the most significant influence on articulation compensation. In conclusion, there was to significant defference between using non using rugae palatinal on the base of obturator while pronbuced the rakum word.
\end{abstract}

Key words: velopharyngeal obturator, insufficiency velopharyngeal, palatal rugae

\begin{abstract}
Abstrak
Penderita lahir dengan celah bibir dan langit-langit merupakan malformasi komponen penting untuk mekanisme velofaringeal, sehingga katup velofaringeal tidak bekerja secara adekuat untuk memungkinkan penutupan nasofaring dan orofaring yang sesuai. Kekurangan mekanisme ini mengakibatkan kesulitan dalam berbicara untuk suara tertentu, kondisi ini disebut insufisiensi velofaringeal. Celah bibir dan langit-langit memerlukan pendekatan multidisiplin ilmu dari ahli bedah mulut dan maksilofasial, ahli bedah plastik, prostodontis hingga ahli terapi bicara. Salah satu penanganan celah langit-langit yaitu melalui pembedahan yang dilanjutkan dengan penggunaan obturatator velofaringeal untuk memperbaiki kualitas bicara. Penambahan rugae palatina pada basis obturator untuk mengembalikan bentuk anatomi palatum sehingga lidah terbiasa dengan kondisi normal. Tujuan dari penelitian ini adalah untuk menganalisis pengaruh pembuatan rugae palatinal pada basis obturator velofaringeal terhadap kualitas produksi bicara. Penelitian ini merupakan pra eksperimental klinis dengan pre and post with control group design dengan tiga bentuk desain obturator velofaringeal yang dibuatkan rugae palatina pada masing-masing obturator. Terdapat 12 sampel yang dibagi menjadi 3 kelompok, yang
\end{abstract}


mana tiap kelompok terdiri atas 4 subjek. Penelitian ini meneliti mengenai udara lolos hidung, hipernasalitas dan kompensasi artikulasi sebelum dan sesudah pemakaian obturator velofaringeal dengan penambahan rugae palatina pada basisnya. Data dianalisis menggunakan uji Kruskal Wallis yang dilajutkan dengan uji Post-hoc Mann- Whitney untuk melihat perbedaan pengaruh pada masing-masing alat saat pengucapan bunyi konsonan maupun kata-kata. Hasil penelitian menunjukkan bahwa semua piranti tidak memberikan pengaruh pada udara lolos hidung, piranti 1 dan 3 memberikan pengaruh paling signifikan pada hipernasalitas dan piranti 2 memberikan pengaruh paling signifikan untuk kompensasi artikulasi. Sebagai kesimpulan, tidak terdapat perbedaan yang bermakna antara tanpa pemakaian piranti dan pemakaian piranti dengan pemberian rugae palatine pada basis obturator saat pengucapan kata ñakunò

Kata kunci: insufisiensi velofaring, obturator velofaringeal, rugae palatina

\section{PENDAHULUAN}

Penderita lahir dengan celah bibir dan langit-langit didefinisikan sebagai malformasi yang melibatkan komponen anatomi penting untuk mekanisme velofaringeal. Langit-langit lunak atau velum merupakan bagian kompleks rongga mulut dan hidung untuk menghasilkan suara lisan atau sengau. Kekurangan mekanisme penutupan nasofaring dan orofaring mengakibatkan kesulitan dalam berbicara untuk suara tertentu, kondisi ini sering disebut sebagai insufisiensi velofaringeal.

Penanganan celah pada langit-langit dapat melalui pembedahan atau palatoplasti, atau tanpa pembedahan yaitu dengan penggunaan obturator velofaringeal dan atau keduanya. Menurunnya fungsi velofaringeal dapat disebabkan oleh karena insufisiensi atau inkompetensi. Insufisiensi velofaringeal merupakan gangguan yang menyebabkan penutupan sfingter velofaringeal yang tidak tepat selama proses berbicara, yang memungkinkan udara keluar melalui hidung (hipernasalitas) bukan melalui mulut. Pemakaian obturator velofaringeal yang diperpanjang sampai ke palatum keras untuk mengatasi hipernasalitas yang menyebabkan bicara sengau dan memperbaiki kualitas bicara. Bicara sengau dan pengucapan huruf masih belum jelas setelah operasi celah langit-langit maka diperlukan pemakaian obturator velofaringeal dan terapi bicara, untuk itu perlu kerjasama antara prostodontis dan ahli terapi bicara. ${ }^{1-3}$

Obturator velofaringeal dapat dibuat dalam berbagai bentuk desain dengan tujuan yang sama. Pada penelitian ini akan diteliti tiga desain obturator dengan penambahan rugae palatina pada tiap basisnya untuk mengembalikan bentuk anatomi palatum sehingga lidah terbiasa dengan kondisi normal tersebut. Kualitas pengucapan bicara merupakan kombinasi fonasi dan artikulasi yang dipengaruhi oleh kontak area antara basis obturator, gigi-gigi anterior, premolar pertama dan lidah. ${ }^{3}$

Salah satu penyebab disfungsi velofaring adalah insufisiensi jaringan setelah perbaikan awal celah palatum (palatoplasti primer), begitu pula dengan fistula palatal sebagai akibat palatoplasti primer. Keduanya menyebabkan bicara hipernasal, emisi udara dari hidung (lolosnya udara selama produksi konsonan) dan kompensasi produksi artikulasi. ${ }^{46}$

Efek primer insufisiensi velofaring adalah keluarnya aliran udara dan hipernasal, sementara efek sekundernya, yaitu kesalahan artikulasi pengucapan (distorsi, substitusi, dan omisi). Masalah komunikasi disebabkan distorsi bicara, resonansi, artikulasi dan gangguan menelan. Tahap perkembangan bahasa menurut Berry \& Einsension adalah: tahap refleks, babbling (dominasi bunyi vokal yang berulang), lalling (mengulangi kata-kata yang diucapkan), echolalia (meniru suara, masih belum dapat dipahami) dan true speech (mengucapkan kata-kata dengan pengulangan suku kata). ${ }^{7-9}$

Rugae palatina merupakan lipatan atau kerutan anatomi yang tidak teratur, merupakan jaringan ikat fibrosa yang terletak pada sepertiga anterior palatum di bawah papila yang tajam. Fungsi rugae palatinal adalah memfasilitasi transportasi makanan ke dalam kavitas oral, mencegah makanan keluar dari mulut dan berpartisipasi dalam pengunyahan makanan, dengan adanya gustatori dan reseptor taktil, maka rugae palatina berkonstribusi untuk persepsi rasa, tekstur makanan dan posisi lidah selama berbicara. $^{10,11}$

Penelitian ini bertujuan untuk mengetahui pengaruh rugae palatina pada basis obturator velofaringeal terhadap kualitas produksi bicara.

\section{BAHAN DAN METODE}

Penelitian ini dilaksanakan di RSGM FKGUnhas bagian Prostodonsi, RSUP dr. Wahidin Sudirohusodo Makassar bagian rehabilitasi medik untuk penilaian kualitas bicara pasien. Penelitian dilakukan pada bulan Juli 2013 sampai Maret 2014. Subyek penelitian adalah pasien pasca palatoplasti dengan insufisiensi velofaringeal, berusia minimal 20 tahun dan bersedia dilakukan penilaian bicara sebelum dan setelah memakai obturator velofaringeal dengan penambahan rugae palatina pada basisnya. 
Penelitian ini adalah penelitian pra eksperimental klinis dengan rancangan pre and post with control design dengan 3 kelompok desain piranti, yaitu: kelompok piranti 1 berupa basis akrilik dengan rugae palatina dan obturator velofaringeal berbahan akrilik, kelompok piranti 2 berupa basis akrilik dengan rugae palatina dan obturator velofaringeal berbahan akrilik yang diberi hole atau lubang ditenganhya, piranti 3 berupa basis akrilik dengan rugae palatina dan obturator velofaringeal dari bahan soft akrilik. Sampel diperoleh sebanyak 12 piranti, terdiri atas 4 subyek yang masing-masing menggunakan 3 desain piranti yang telah disebutkan.

Sebelum memulai penelitian, pasien diberikan penjelasan mengenai prosedur penelitian, dan cara penggunaan piranti. Seluruh tahapan penelitian disampaikan dan apabila disetujui diminta untuk menandatangani informed consent. Pemeriksaan suara yang dinilai adalah pengukuran hipernasal atau suara sengau pada pengucapan konsonan dan kata, pengukuran udara lolos hidung pada waktu pengucapan konsonan dan kata dengan melihat ada atau tidak embun pada cermin yang diletakkan di depan hidung, serta pengukuran kompesasi artikulasi yaitu bagaimana udara dari paru-paru mengalami hambatan hingga keluar dari mulut saat mengucapkan konsonan dan kata.

Pada pengukuran hipernasal, yang dinilai adalah suara hipernasal (sengau) pada pengucapan vokal menengah dan tinggi (a dan i), serta konsonan hambat ( $\mathrm{p}, \mathrm{b}, \mathrm{g}, \mathrm{t}$, dan $\mathrm{d}$ ). Pada pengukuran udara lolos hidung, yang dinilai adalah penilaian udara lolos melalui hidung pada waktu pengucapan huruf $/ \mathrm{p} /$ atau $/ \mathrm{k} /$, dengan cara melihat ada atau tidaknya embun pada cermin yang diletakkan tepat di depan lubang hidung. ${ }^{12,13}$

Pada penilaian artikulasi, fonasi dan vokal, yang dinilai adalah bunyi vokal yang dihasilkan dari udara paru-paru melewati rongga mulut tanpa hambatan organ bicara, yang membedakannya hanya bentuk bibir, lidah dan rahang serta bunyi konsonan dihasilkan melalui hambatan di daerah mulut untuk memproduksinya. Konsonan ini dibedakan berdasarkan daerah artikulasi yaitu konsonan bilabial, labiodental, linguodental, linguopalatal, linguovelar, dan konsonan glotal, berdasarkan cara artikulasi artinya bagaimana udara dari paru-paru mengalami hambatan hingga keluar dari mulut, konsonan ini dibedakan atas konsonan letupan, frikatif, nasal, getar, lateral (ujung lidah menyentuh rugae palatenal dan udara keluar melalui samping lidah) dan konsonan luncuran, berdasarkan bergetar tidaknya pita bicara yaitu bergetar : /b/, /d/, /g//,/v///z/, /m/, /l/, $/ \mathrm{r} /, / \mathrm{n} /, / \mathrm{ny} /$ dan $/ \mathrm{ng} /$ dan tidak bergetar: /p/, /t///k/, /f/, $/ \mathrm{c} /, / \mathrm{s} /, / \mathrm{sy} /, / \mathrm{h} / .^{12,13}$

\section{HASIL}

Tabel 1 memperlihatkan tidak terdapat perbedaan udara lolos hidung pada konsonan pa, ka dan ta antara yang tidak menggunakan piranti dengan yang menggunakan piranti 1 , piranti 2 , dan piranti 3. (p> $0,005)$

Tabel 2 memperlihatkan tidak terdapat perbedaan udara lolos hidung pada kata óbapak, rakun, sangu, juri, kamar dan garamô antara yang tidak menggunakan piranti dengan yang menggunakan piranti 1, piranti 2, dan piranti 3. $(\mathrm{p}>0,005)$

Tabel 1. Hasil Analisis Kruskal Wallis untuk udara lolos hidung pada pengucapan konsonan berdasarkan piranti yang digunakan

\begin{tabular}{ccccccc}
\hline Konsonan & & $\mathrm{n}$ & Minimun & Maksimun & Rerata \pm SD & $\mathrm{p}$ \\
\hline $\mathrm{Pa}$ & Tanpa Piranti & 4 & 0,70 & 3,40 & $2,05 \pm 1,14$ & \\
& Piranti 1 & 4 & 0,00 & 2,20 & $1,02 \pm 0,91$ & 0,424 \\
& Piranti 2 & 4 & 0,00 & 1,90 & $0,95 \pm 1,10$ & \\
& Piranti 3 & 4 & 0,00 & 1,80 & $0,82 \pm 0,96$ & \\
& Tanpa Piranti & 4 & 1,10 & 2,80 & $1,72 \pm 0,78$ & \\
$\mathrm{Ka}$ & Piranti 1 & 4 & 0,00 & 2,60 & $1,20 \pm 1,08$ & 0,753 \\
& Piranti 2 & 4 & 0,00 & 3,10 & $1,05 \pm 1,46$ & \\
& Piranti 3 & 4 & 0,00 & 2,30 & $1,20 \pm 1,22$ & \\
& Tanpa Piranti & 4 & 0,30 & 4,30 & $2,32 \pm 1,81$ & \\
& Piranti 1 & 4 & 0,00 & 1,60 & $0,70 \pm 0,82$ & \\
& Piranti 2 & 4 & 0,00 & 1,50 & $1,05 \pm 0,70$ & \\
\end{tabular}


Tabel 2. Analisis Kruskal Wallis untuk udara lolos hidung berdasarkan pe ngucapan kata dan piranti yang digunakan

\begin{tabular}{|c|c|c|c|c|c|c|}
\hline Pengucapan kata & Piranti yang digunakan & $\mathrm{n}$ & Minimun & Maksimun & Rerata \pm SD & $\mathrm{p}$ \\
\hline \multirow[t]{4}{*}{ Bapak } & Tanpa Piranti & 4 & 0,30 & 2,60 & $1,60 \pm 0,96$ & \multirow{4}{*}{0,710} \\
\hline & Piranti 1 & 4 & 0,20 & 2,70 & $1,45 \pm 1,19$ & \\
\hline & Piranti 2 & 4 & 0,00 & 3,60 & $1,70 \pm 1,47$ & \\
\hline & Piranti 3 & 4 & 0,00 & 2,60 & $0,87 \pm 1,23$ & \\
\hline \multirow[t]{4}{*}{ Rakun } & Tanpa Piranti & 4 & 1,00 & 3,00 & $2,12 \pm 0,84$ & \multirow{4}{*}{0,537} \\
\hline & Piranti 1 & 4 & 0,00 & 2,80 & $1,37 \pm 1,16$ & \\
\hline & Piranti 2 & 4 & 1,40 & 2,90 & $2,15 \pm 0,71$ & \\
\hline & Piranti 3 & 4 & 0,70 & 2,70 & $1,52 \pm 0,89$ & \\
\hline \multirow[t]{4}{*}{ Sangu } & Tanpa Piranti & 4 & 1,80 & 3,50 & $2,77 \pm 0,86$ & \multirow{4}{*}{0,758} \\
\hline & Piranti 1 & 4 & 1,60 & 3,20 & $2,40 \pm 0,66$ & \\
\hline & Piranti 2 & 4 & 1,10 & 3,00 & $2,12 \pm 0,80$ & \\
\hline & Piranti 3 & 4 & 1,70 & 2,90 & $2,32 \pm 0,61$ & \\
\hline \multirow[t]{4}{*}{ Juri } & Tanpa Piranti & 4 & 2,10 & 3,30 & $2,95 \pm 0,57$ & \multirow{4}{*}{0,857} \\
\hline & Piranti 1 & 4 & 1,80 & 3,80 & $2,70 \pm 0,84$ & \\
\hline & Piranti 2 & 4 & 1,70 & 3,80 & $2,62 \pm 0,96$ & \\
\hline & Piranti 3 & 4 & 2,00 & 3,70 & $2,70 \pm 0,72$ & \\
\hline \multirow[t]{4}{*}{ Kamar } & Tanpa Piranti & 4 & 0,40 & 2,50 & $1,90 \pm 1,01$ & \multirow{4}{*}{0,690} \\
\hline & Piranti 1 & 4 & 0,30 & 2,40 & $1,55 \pm 0,90$ & \\
\hline & Piranti 2 & 4 & 0,20 & 2,60 & $1,70 \pm 1,04$ & \\
\hline & Piranti 3 & 4 & 0,00 & 2,60 & $1,60 \pm 1,12$ & \\
\hline \multirow[t]{4}{*}{ Garam } & Tanpa Piranti & 4 & 1,60 & 2,80 & $2,37 \pm 0,57$ & \multirow{4}{*}{0,429} \\
\hline & Piranti 1 & 4 & 0,00 & 2,40 & $1,50 \pm 1,05$ & \\
\hline & Piranti 2 & 4 & 0,00 & 2,30 & $1,62 \pm 1,09$ & \\
\hline & Piranti 3 & 4 & 0,00 & 2,80 & $1,42 \pm 1,14$ & \\
\hline
\end{tabular}

$p>0,05$

Tabel 3 memperlihatkan kelompok yang mempunyai perbedaan hipernasalitas dengan tes konsonan ф́a, ka, dan ta adalah kelompok tanpa piranti dan piranti 1,2,3 sedangkan antara kelompok piranti 1 dan 2, kelompok piranti 1 dan piranti 3 serta kelompok piranti 2 dan kelompok piranti 3 tidak terdapat perbedaan hipernasalitas.

Tabel 4 memperlihatkan kelompok yang mempunyai perbedaan hipernasalitas dengan tes kata óapak, rakun, sangu, juri, kamar dan garamôadalah kelompok tanpa piranti dan piranti 1,2,3 pada semua jenis kata, sedangkan antara kelompok piranti 1 dan 2, kelompok piranti 1 dan 3 ada perbedaaan pada kata ógaramô kelompok piranti 2 dan piranti 3 ter- dapat perbedaan yang signifikan pada kata ğuriôdan ǵaramô

Tabel 3. Analisis Post-hoc Mann-Whitney untuk hipernasal pengucapan konsonan

\begin{tabular}{ccccc}
\hline \multirow{2}{*}{ Perbandingan piranti } & \multicolumn{3}{c}{ Konsonan } \\
\cline { 3 - 5 } Tanpa Piranti & Piranti 1 & $0,040^{*}$ & $0,032^{*}$ & $0,040^{*}$ \\
& Piranti 2 & $0,040^{*}$ & $0,040^{*}$ & 0,127 \\
& Piranti 3 & $0,008^{*}$ & $0,022^{*}$ & $0,013^{*}$ \\
Piranti 1 & Piranti 2 & 1,000 & 0,495 & 0,760 \\
& Piranti 3 & 0,317 & 0,495 & 0,096 \\
Piranti 2 & Piranti 3 & 0,317 & 0,186 & 0,533 \\
\hline
\end{tabular}

*signifikan dengan uji Mann-Whitney $(\mathrm{p}<0,05)$

Tabel 4. Hasil Analisis Post-hoc Mann-Whitney untuk hipernasal pengucapan kata dan alat yang digunakan

\begin{tabular}{|c|c|c|c|c|c|c|c|}
\hline \multirow{2}{*}{\multicolumn{2}{|c|}{ Perbandingan piranti }} & \multicolumn{6}{|c|}{ Kata } \\
\hline & & Bapak & Rakun & Sangu & Juri & Kamar & Garam \\
\hline \multirow[t]{3}{*}{ Tanpa Piranti } & Piranti 1 & $0,040^{*}$ & 0,127 & $0,040^{*}$ & $0,011^{*}$ & $0,011^{*}$ & $0,011 *$ \\
\hline & Piranti 2 & $0,040 *$ & $0,013 *$ & $0,040 *$ & $0,008^{*}$ & $0,011 *$ & 0,317 \\
\hline & Piranti 3 & $0,032 *$ & $0,008 *$ & $0,032 *$ & $0,011 *$ & $0,013 *$ & $0,008 *$ \\
\hline \multirow[t]{2}{*}{ Piranti 1} & Piranti 2 & 1,000 & 0,061 & 1,000 & 0,317 & 0,186 & $0,040 *$ \\
\hline & Piranti 3 & 0,127 & 0,127 & 0,127 & 0,186 & 0,495 & $0,040 *$ \\
\hline Piranti 2 & Piranti 3 & 0,127 & 0,127 & 0,127 & $0,040^{*}$ & 0,495 & $0,011 *$ \\
\hline
\end{tabular}

*signifikan dengan uji Mann-Whitney $(\mathrm{p}<0,05)$ 
Tabel 5 memperlihatkan kelompok yang mempunyai perbedaan kompensasi artikulasi dengan tes pengucapan konsonan q́a, ka, dan taô adalah kelompok tanpa piranti dan piranti 2, perbedaan kompensasi artikulasi pada pengucapan konsonan óa dan kaó adalah kelompok tanpa piranti dan kelompok piranti 1 dan piranti 3, terdapat perbedaan pengucapan konsonan hanya pada pengucapan óaô untuk kelompok piranti 1 dan piranti 2, sedangkan tidak ada perbedaan yang bermakna pada pengucapan konsonan q́a, ka , dan taôuntuk piranti 1 dan piranti 3, pada kelompok piranti 2 dan piranti 3 terdapat perbedaan yang signifikan pada pengucapan konsonan áaô

Tabel 5. Hasil Analisis Post-hoc Mann-Whitney untuk kompensasi artikulasi pada pengucapan konsonan dan penggunaan piranti

\begin{tabular}{ccccc}
\hline \multirow{2}{*}{ Perbandingan piranti } & \multicolumn{3}{c}{ Konsonan } \\
\cline { 3 - 5 } & & $\mathrm{Pa}$ & $\mathrm{Ka}$ & $\mathrm{Ta}$ \\
\hline \multirow{2}{*}{ Tanpa Piranti } & Piranti 1 & $0,040^{*}$ & $0,040^{*}$ & 0,495 \\
& Piranti 2 & $0,040^{*}$ & $0,011^{*}$ & $0,013^{*}$ \\
& Piranti 3 & $0,032^{*}$ & $0,013^{*}$ & 0,096 \\
Piranti 1 & Piranti 2 & 1,000 & 0,186 & $0,011^{*}$ \\
& Piranti 3 & 0,127 & 0,096 & 0,186 \\
Piranti 2 & Piranti 3 & 0,127 & 0,495 & $0,040^{*}$ \\
\hline
\end{tabular}

*signifikan dengan uji Mann-Whitney $(\mathrm{p}<0,05)$

Kelompok yang mempunyai perbedaan kompensasi artikulasi dengan tes kata óapak, rakun, sangu, juri, kamar dan garamô adalah kelompok tanpa piranti dan piranti 1,2,3 pada semua jenis kata kecuali kata óakunô sedangkan antara kelompok piranti 1 dan 2 terdapat perbedaan pada pengucapan kata óangu dan kamarô kelompok piranti 1 dan 3 tidak ada perbedaan pada semua kata, sedangkan kelompok piranti 2 dan piranti 3 tidak terdapat perbedaan yang signifikan pada kata semua kata.

Tabel 6. Hasil Analisis Post-hoc Mann-Whitney untuk kompensasi artikulasi berdasarkan pengucapan kata dan penggunaan alat

\begin{tabular}{cccccccc}
\hline \multirow{2}{*}{$\begin{array}{c}\text { Perbandingan } \\
\text { piranti }\end{array}$} & \multicolumn{6}{c}{ Kata } \\
\cline { 2 - 8 } & Bapak & Rakun & Sangu & Juri & Kamar & Garam \\
\hline Tanpa & Piranti 1 & $0,008^{*}$ & 0,495 & $0,040^{*}$ & $0,046^{*}$ & $0,040^{*}$ & $0,013^{*}$ \\
Piranti & Piranti 2 & $0,013^{*}$ & 0,061 & $0,008^{*}$ & $0,011^{*}$ & $0,011^{*}$ & $0,040^{*}$ \\
& Piranti 3 & $0,013^{*}$ & 0,127 & $0,013^{*}$ & $0,008^{*}$ & $0,022^{*}$ & $0,011^{*}$ \\
Piranti 1 & Piranti 2 & 0,127 & 0,096 & $0,011^{*}$ & 0,874 & $0,040^{*}$ & 0,096 \\
& Piranti 3 & 0,127 & 0,317 & 0,096 & 0,505 & 0,186 & 0,495 \\
Piranti 2 & Piranti 3 & 1,000 & 0,127 & 0,127 & 0,0317 & 0,317 & 0,186 \\
\hline *signifikan dengan uji Mann-Whitney $(\mathrm{p}<0,05)$ & &
\end{tabular}

\section{PEMBAHASAN}

Hasil penelitian menunjukkan pengaruh penggunaan obturator velofaringeal dengan rugae pala- tina terhadap kualitas bicara pasien insufisiensi velofaring pasca palatoplasti menunjukkan bahwa pemeriksaan udara lolos hidung tidak terdapat perbedaan yang bemakna pada pengucapan konsonan ñpa, ka dan taòserta pengucapan kata ñ bapak, rakun, sangu, juri, kamar, dan garamò antara kelompok tanpa penggunaan piranti dan kelompok yang menggunakan piranti 1, 2, dan 3 dengan uji KruskalWallis diperoleh nilai $p>0,005$. Hasil analisis hipernasalitas pada pengucapan konsonan óa dan kaôterdapat perbedaan hipernasalitas antara yang tidak menggunakan piranti dengan yang menggunakan piranti 1, 2, dan 3, hasil uji Kruskal Wallis diperoleh $\mathrm{p}<0,005$, untuk melihat perbedaan dilanjutkan dengan post-hoc Mann Whitney.

Hasil analisis uji Kruskal Wallis untuk kompensasi artikulasi pada pengucapan konsonan óa, ka, dan taôberdasarkan piranti yang digunakan menunjukkan bahwa terdapat perbedaan yang bermakna antara yang tidak menggunakan piranti dengan yang menggunakan piranti 1,2 dan 3 ( $\mathrm{p}<$ 0,05 ), untuk melihat perbedaannya dilanjutkan dengan uji post-hoc Mann-Whitney diperoleh hasil terdapat perbedaan yang paling bermakna yaitu antara tanpa menggunakan piranti dengan penggunaan piranti 2, dan perbedaan yang bermakna antara penggunaan piranti 1 dan 2 untuk konsonan áaôserta antara penggunaan piranti 2 dan 3 untuk konsonan áaô

Hasil analisis dengan Kruskal Wallis pada pengucapan kata óapak, sangu, juri, kamar dan garamôterdapat perbedaan yang bermakna untuk kompensasi artikulasi antara yang tidak menggunakan piranti dan yang menggunakan piranti 1, 2, dan 3 kecuali pada kata rakun ( $p>0,05)$. Perbedaan dapat lebih jelas dilihat pada uji post-hoc Mann Whitney antara tanpa menggunakan piranti dengan menggunakan piranti 1, 2 dan 3 kecuali pada kata óakunô tidak terdapat berbedaan yang bermakna. Perbedaan yang bermakna juga terlihat pada pengucapan kata óangu dan kamarôantara penggunaan piranti 1 dan piranti 2 yaitu $\mathrm{p}<0,05$.

Pada penelitian ini yang dipakai adalah bunyi konsonan bilabial stop, tak bersuara dengan (p), bunyi konsonan ini dihasilkan dengan artikulasi bibir bawah dan titik artikulasi bibir atas,udara yang keluar dari paru-paru tidak menggetarkan pita suara sehingga disebut bunyi tak bersuara, udara yang keluar melewati rongga mulut disebut bunyi oral, sehingga pada pengucapan konsonan q́a, ka, dan taô untuk udara lolos hidung tidak bermakna antara yang menggunakan piranti dan yang tidak menggunakan piranti. $^{14}$

Bunyi konsonan lainnya yaitu pengucapan áaô merupakan bunyi konsonan apiko alveolar, letus, 
oral, tak bersuara dilambangkan dengan (t). Bunyi dihasilkan oleh artikulasi ujung lidah dan artikulasi lengkung akar gigi, bunyi ini seperti bunyi konsonan bilabial stop yaitu tidak menggetarkan pita suara dan udara yang dikeluarkan melewati rongga mulut. Bunyi konsonan ớô merupakan bunyi konsonan dorso velar, letus, oral, tak bersuara yang dilambangkan dengan (k), sama seperti dua konsonan sebelumnya. ${ }^{14}$

Artikulator dapat dibagi menjadi statik atau pasif yang meliputi gigi geligi, palatum keras atau durum, dan ridge alveolar. Dua elemen utama dipengaruhi oleh perubahan penempatan artikulasi lidah dengan langit-langit keras palatum durum dan perubahan mukosa ridge alveolar dan penurunan fungsi resonator rongga mulut. ${ }^{15}$

Masalah dengan resonansi mengacu pada gangguan, seperti hipernasalitas, yang terjadi di atas glotis selama produksi vokal. Gangguan hipernasal terjadi selama produksi suara vokal yang memerlukan penutupan sesuai ruang hidung dari ruang oral. Hasil penelitian ini menunjukkan perbedaan hipernasalitas pada pengucapan konsonanộa, ka dan taôkelompok tanpa piranti dengan menggunakan piranti 1 yang mana speech bulb dari bahan akrilik dan piranti 3 yaitu speech bulb dari bahan permanen soft liner atau soft acrylic. ${ }^{16}$

Masalah artikulasi mungkin berkaitan dengan kesulitan menciptakan sejumlah penekanan lisan yang diperlukan untuk menghasilkan bunyi frikatif, afrikatif, oral stop, lateral, dan suara letup $(/ \mathrm{f} /$, / th /, / v /, / s /, / z /, / sh /, / ch /, / j/, / p /, / b /, / d /,/ k/, / g/, / t /, / 1/, / r /, / y /, dan / w /). Pada mekanisme velopharyngeal melakukan fungsi tepat untuk menutup rongga hidung, udara dari paru-paru menghambat untuk menghasilkan suara tersebut. Kompensasi artikulasi terjadi ketika pasien mencoba untuk membentuk secara patologis aliran udara lebih ke posterior di saluran vokal daripada di lokasi normal palatum anterior, gigi, dan lidah. ${ }^{16}$

Literatur mengindikasikan bahwa antara 5 dan $50 \%$ kasus yang mendapatkan palatoplasti awal untuk mengoreksi celah langi-langit (sekitar 20\%) masih terdapat disfungsi velofaringeal setelah perbaikan awal baik itu insufisiensi, inkompetensi atau keduanya. Pinto, Dalben dan Pegararo-Krook menyatakan bahwa perawatan prostetik yang melibatkan insufisiensi velofaringeal dengan menggunakan obturator faringeal (speech bulbs) dan hasil pendekatan ini tergantung pada derajat hipernasalitas, tipe kompensasi artikulasi yang digunakan, umur, dan kondisi gigi geligi bersama kondisi struktur dan fungsi palatum serta dinding faring. ${ }^{17}$

Penelitian ini berhubungan dengan penambahan rugae palatina pada basis tiap piranti untuk mem- berikan kondisi normal di dalam mulut sehingga pada saat pengucapan kata yang mencakup bunyi konsonan apiko alveolar dengan lambing (r), yaitu bunyi yang dihasilkan oleh artikulator ujung lidah dan titik artikulasi lengkung kaki gigi, bunyi ini dihasilkan dengan menggetarkan lidah sehingga udara yang keluar melewati rongga mulut, uvula terangkat menghasilkan getaran selaput suara. ${ }^{14}$ Pada penelitian ini diwakili dengan kata óakunô namun tidak terdapat perbedaan yang bermakna tanpa pemakaian piranti dengan piranti 1,2 dan 3, kondisi ini sesuai dengan celah palatum sebelumnya pada tiap subyek penelitian sebatas daerah velum atau palatum lunak, dan tidak melibatkan palatum durum sehingga pasien secara fisiologis terbiasa dengan adanya rugae palatina, oleh karena itu tidak terdapat perbedaan yang bermakna pada pengucapan kata ớakunô Kondisi ini disebabkan oleh kompensasi artikulasi pasien, dalam hal ini peran ahli terapi bicara sangat diperlukan untuk mengubah kebiasaan ini. Bunyi konsonan fronto palatal, oral, bersuara dengan lambang (j) merupakan bunyi konsonan yang dihasilkan dengan menempatkan lidah bagian depan sebagai artikulator ke titik artikulasi langit-langit keras atau palatum durum dimana terdapat rugae palatine, sehingga pada saat bunyi dihasilkan, udara melewati rongga mulut, menggetarkan pita suara. ${ }^{14}$ Pada penelitian ini diwakili oleh kata ĝuriôterlihat perbedaan yang paling bermakna antara yang tidak menggunakan piranti dengan yang menggunakan piranti 1,2 dan 3 tiap basis piranti dimodifikasi dengan pembentukan rugae palatina. Bunyi konsonan dorso velar, dilambangkan dengan (g), bunyi yang dihasilkan dengan artikulator lidah bagian belakang (dorsum) dengan velum (langit-langit lunak) sebagai artikulasi sehingga pada saat bunyi dihasilkan akan menggertarkan pita suara uvula terangkat naik menutup rongga hidung dan udara keluar melalui mulut. ${ }^{14}$ Pada penelitian ini diwakili dengan kata ógaramô terlihat adanya perbedaan yang bermakna pada pengucapan kata garam untuk kelompok tak memakai piranti dengan kelompok yang memakai piranti 1, 2 dan 3 .

Sebuah literatur menjelaskan perkiraan ukuran orifisum velofaringeal dimana pada penelitian menunjukkan bahwa artikulasi secara signifikan berbanding terbalik dengan ukuran orifisum $(r=0,665$ dan $\mathrm{t}=2,52$ ). Meningkatkan ukuran orifisum akan mengurangi artikulasi bicara yang adekuat. Selain itu, ada hubungan yang signifikan secara statistik antara nasalitas dan ukuran orifisum velofaringeal pada pasien yang ditangani secara prostodontik ( $\mathrm{r}=$ 0,785 dan $t=3,59$ ), jika ukuran orifisium daerah velofaringeal pada obturator ditingkatkan, akan disertai peningkatan nasalitas. ${ }^{18}$ 
Nasalitas menjadi ditekankan dengan peningkatan ukuran orifisum velofaringeal. Tampaknya masuk akal untuk mengasumsikan bahwa peningkatan laju aliran udara melalui jumlah nada resonansi terjadi di ruang hidung. Hal ini dapat diperbaiki dengan penatalaksanaan prostetik yang memadai yang juga dapat menghilangkan distorsi elemen suara tekanan tertentu, seperti suara ' $\mathrm{p} \cdot{ }^{18}$ Pernyataan ini sesuai dengan hasil penelitian kami yaitu pada pemeriksaan hipernasalitas terdapat perbedaan yang signifikan pada pengucapan konsonan q́aô antara kelompok tanpa piranti dan kelompok piranti kedua dengan speech bulb dibuatkan hole $(\mathrm{r}=0,7 \mathrm{dan} \mathrm{t}=3)$.

Kesimpulan penelitian ini adalah semua piranti tidak memberikan pengaruh pada udara lolos hidung, piranti 1 dan 3 memberikan pengaruh paling signifikan pada hipernasalitas dan piranti 2 memberikan pengaruh paling signifikan untuk kompensasi artikulasi dan tidak terdapat perbedaan yang bermakna antara tanpa pemakaian piranti dan pemakaian piranti dengan pemberian rugae palatina pada basis obturator saat pengucapan kata ñakunò namun terlihat adanya perbedaan yang paling bermakna pada saat pengucapan kata ñjuriò sehingga disarankan untuk penelitian selanjutnya dilakukan terapi bicara selama penggunaan piranti agar kompensasi artikulasi dapat dinilai lebih akurat.

\section{Daftar Pustaka}

1. Sharmila MR, N Kalavathy, J Sridevi, M Shetty M, Kumar Roshan, Premnath. Prosthetic rehabilitation of velopharyngeal insufficiency: report of two cases. SRM University J Dent Sci 2011: 2(3); 261-5.

2. Tajrin A. Velofaringeal insufisiensi dan penatalaksanaannya. Majalah PABMI. 2012:15(2); 78-84.

3. Hassel JA, Holste T. Improving the speech function of maxillary complete denture: a pilot study. Int $\mathbf{J}$ Prosthodont 2006: 19(5); 499-503.

4. Pinto NHJ, Dalben GDS, Pegoraro-Krook PIM. Speech intelligibility of patients with cleft lip and palate after placement of speech prosthesis. Cleft Palate- Craniofacial J 2007: 44(6); 635-41.

5. Gregio-Lima MA, Marino, Krook-Pegoraro IM, Barbosa AP, Aferri CH, Dutka RCDJ. Nasalance and nasality at experimental velopharyngeal openings in palatal prothetisis: a case study. J Appl Oral Sci 2011: 19(6); 616-22.
6. Kummer AW. Speech therapy for cleft palate or velopharyngeal dysfunction (VPD). Cincinnati Childrenô Hospital Medical Centre. <.http://www.c incinnatichildrens.org/asset/8a97951944fb.pdf> (1 3 februari 2013).

7. Tuna SH, Pekkan G, Gumus H.O, Aktas A. Prosthetic rehabilitation of velopharyngeal insufficiency: pharyngeal obturator prostheses with different retention mechanisms. Euro J Dent 2010: 4: 81-7.

8. Ramya R, Balasubramaya KV. Speech aid prosthesis-case report of obturation of partial soft palate. J Dental Sciences and Research 2011: 2(2);1-5.

9. Sell D, Mars M, Worrell E. Process and outcome study of multidiciplinary prosthetic treatment for velopharyngeal dysfunction. Int $\mathrm{J}$ Lang Commun Disord 2006: 41(5); 495-511.

10. Jawad IA. Comparison of rugae pattern between dentate and edentulous patients in Iraqi sample. AlRafidain Dent J 2010: 10(2); 265-71.

11. Tanaka A, Kodaira Y, Ishizaki K, Sakurai K. Influence of palatal surface shape of dentures on food perception. J Oral Rehabil 2008: 35(10); 715721.

12. Melo DP, Ramalho MSSC, Perillo VCA, Rodrigues LCB. Intensive speech theraphy and cleft palate: case report. CEFAC. 2013: 15(4); 1019-1023.

13. Kuehn DP. Speech evaluation and treatment for patients with cleft palate. Am J Speech- Lang Pat 2003; 12: 103-109.

14. Marsono. Fonetik. $4^{\text {th }}$ ed Yogyakarta. Gadja Mada Univercity Press 2009; 61-99.

15. Artjomenko V, Vidziz A, Broka K. The assessment of speech quality and intellibility after replacement of lost teeth with removable denture: review of literature. Acta Chirurgica Latviensis 2012; 12: 72-7.

16. Costello JB, Ruiz LR, Turvey AT. Velopharyngeal insufficiency in patients with cleft palate. Oral Maxillofacial Surg Clin N Am 2002; 14: 539-51.

17. Maciel HN, Evangelista M, Carneiro H, Alves DJ, Rillo CDJ, Ines M. Speech therapy for compensatory articulations and velopharyngeal function: a case report. J Appl Oral Sci 2011; 19(6): 679-84.

18. Dakkak El-M. Adequacy of velopharyngeal closure and speech competency following prosthetic management of soft palate resection. J Dent Saudi 1991; 1(3): 3-7. 